\title{
Water eco-civilization urban construction in Shandong Province from the perspective of systematic governance
}

\author{
Jinghao Wang, Yue Sun, Fang Liu+, Wang Miao, Wanxiong Song \\ School of Public Administration, Shandong Normal University, Jinan Shandong 250014, China \\ School of Public Administration, Shandong Normal University, Jinan Shandong 250014, China \\ School of Public Administration, Shandong Normal University, Jinan Shandong 250014, China \\ School of Business Administration, QILU University of Technology, Jinan, 250353, China \\ School of Public Administration, Shandong Normal University, Jinan Shandong 250014, China \\ 17864191786@139.com, mango950506@163.com, Liufang7698@126.com \\ Miao2011sd@163.com,m15033281040@163.com
}

\begin{abstract}
Keywords: systematic governance; water eco-civilization urban construction; Shandong Province Abstract. Water supply is a prerequisite for urban development, water development, not only to consider the urban water resources on the socio-economic development of carrying capacity, but also to consider the quality of water, taking into account the water environment and water ecology of the growing water pollution carrying capacity. From the perspective of systematic governance, this paper analyzes the present situation and problems of water eco-civilization urban construction in Shandong Province, Analyze the paths of constructions, water utilization, water ecological environment and water management, water security, water culture, and strive for " Better City, Better Life " ultimate goal.
\end{abstract}

\section{Introduction}

With the sustainable development of urban economy, water crisis has become increasingly prominent, which requires us to restore a good urban water ecological environment. Researchers have used the method of water crisis management with less research method, research method and single traditional management method, but this method has not adapted to the demand of urban ecological construction and system management in new form. water eco-civilization urban construction from the perspective of systematic governance, the city should be regarded as a living organism, focusing on the integration and balance of nature and society, economic development and ecological environment, and mobilizing the participation of government and society. This paper first analyzes the significance of water eco-civilization urban construction from the perspective of systematic governance, and gives concrete measures based on the evaluation of current situation.

\section{The significance of water eco-civilization urban construction in Shandong Province from the perspective of systematic governance}

\section{To solve the realities of the city, to protect people's lives and property}

On the one hand, the acceleration of urbanization has promoted the improvement of economic development. However, the condition of water environment restricts the operation of economy, and the healthy water supply mechanism can guarantee the stable development of economy. On the other hand, with the acceleration of the modernization process, the living standard of the public is increasing day by day, and people have higher demands on the living environment. The systematic governance of water environment can help to improve the quality of the people's living environment while ensuring the purpose of flood prevention and disaster prevention and the safety of people's life and property. In

\footnotetext{
+ Corresponding author. E-mail address: liufang7698@126.com.
} 
addition, the city's environmental condition also directly determines the investment value of the city, affecting the decision-making of investors, restricting the city's economic development.

To protect the water environment, enhance self-repair capacity of the water environment. The systematic governance of water environment can make the water infrastructure more perfect, promote the development of modern water conservancy, guarantee the smooth water system, improve the quality of water resources. ${ }^{(1)}$ While providing more clean water for the community can be used to improve the urban water environment, effectively alleviate the social water crisis.

To enhance the level of modern urban development, help build a modern national governance system. According to the 18th CPC National Congress and the Third Plenary Session of the 18th CPC Central Committee on the spirit of ecological civilization and General Secretary Jinping Xi put forward the "water-saving priority, spatial balance, systematic governance, two-handed effort," 16 words water instruction. Governance methods to carry out the scientific system of water control and integration of new urbanization development, co-ordinate the landscape elements of Lake Forest Lake to build a community of life in order to effectively crack the new normal water problems. In addition, the systematic governance of water environment conforms to the development goal of modernization, improves the water carrying capacity of urban economic and social development, makes the urban development potential be further excavated, and ecological management is more scientific and effective. ${ }^{2}$ This is conducive to speed up the construction of a resource-saving and environment-friendly society, promote the completion of modern national governance system, to build modern national governance system.

\section{Water eco-civilization urban construction in Shandong Province present situation and the question analysis}

Efficient water-saving system is facing greater challenges, low water use efficiency. Urban water demand is growing, while the amount of urban water resources is limited, the majority of the city's local water resources are close to or reach the limit of development and utilization, part of the city's groundwater has been in overdraft status. Water-saving scientific and technological innovation lack of effective incentive mechanism, water-saving publicity and education and social supervision efforts to be further strengthened. Mechanisms to encourage public participation in water-saving societies are not yet sound.

The main function of eco - environmental system of rivers and lakes needs to be strengthened. Shandong Province is located in warm temperate monsoon climate zone,.In the process of rapid urbanization, the urban ground hardening rate is high, making it difficult to infiltrate rainwater. In addition, urban drainage facilities are lagging behind. Urban sewers are narrow, aging and congested, resulting in lower urban drainage capacity. Shandong Province, cement and other road coverage is far more than grassland and other green vegetation coverage. In 2015 the per capita urban road is $24.70 \mathrm{~m}$ ${ }^{2}$, the per capita park green area is $16.37 \mathrm{~m}^{2}$, built area green coverage rate of less than $50 \%$, only $42.12 \%$. The problem of urban waterlogging is becoming more and more serious. It is imperative to strengthen the management of urban rainwater.

Modern water resources management system needs to be improved. Under the new situation of implementing the most stringent water resources management system step by step, the task of water control in Shandong Province is arduous and complicated, which puts forward higher requirements for the smooth development of meticulous and modernized water resources management and optimization. Shandong Province, watershed management and water management in the management mechanism has not yet been a good integration, the province's water resources management system has not yet

\footnotetext{
(1) Smith,Laurence \& Inman,Alex, et al. Mitigation of diffuse water pollution from agriculture in England and China, and the scope for policy transfer[J].Land use policy.61(4),2017:208-219.

(2) Broman,Goran \& Robert,Karl-Henrik, et al. Science in support of systematic leadership towards sustainability[J]. Journal of cleaner production.140(1).2017:1-9.
} 
been fully established, wading management mechanism has not yet fully rationalized, not yet fully implemented water integration.

Water pollution increased the threat to the residents of production and living water security. With the development of the economy, the proportion of the first, second and tertiary industries is constantly changing, the structure of water consumption is changing, the discharge of sewage is increasing day by day, and the types of pollutants are becoming new. At the same time, due to the construction of urban sewage treatment plants and supporting pipe network facilities lagged behind, industrial waste water discharge compliance rate is low, a large number of industrial wastewater, domestic sewage without any purification treatment directly discharged into the water, far exceeding the river's sewage capacity, Serious water pollution, ${ }^{\left({ }^{1}\right.}$ a serious threat to the health of the people.

Water culture protection and overall planning need to be strengthened. Shandong Province has a long history, left a valuable legacy for water eco-civilization urban construction. However, due to age, has 2600 years of history of the spa culture are mostly character story legend, Furukawa ancient rhyme of the historical ruins are mostly destroyed in the development process, the terminal canal culture gradually disappear, historical and cultural heritage and modern red culture lack of Logical one, complement each other protection planning program.

\section{Exploration on the path of water eco-civilization urban construction in Shandong Province from the perspective of systematic governance}

Optimize the use of water resources. Firstly, we should start from the source to improve the supply capacity of water resources, so that surface water, groundwater, external water transfer, unconventional water resources are optimized configuration. ${ }^{(2)}$ In the long-term development, the construction of reservoirs is an effective way to solve the problem of urban water supply shortage, which can alleviate the uneven distribution of surface water seasons, in addition to its comprehensive benefits of flood control, power generation, irrigation, fisheries, tourism, ecological environment obviously. Secondly, we must strictly implement the total water consumption, water efficiency, double control measures to promote water-saving society.

Build a benign water ecological environment. Water ecological environment factors involved in a wide range, first of all should strengthen the protection of water sources and ecological restoration, water conservation, built a sustained, stable, fine, complete ecosystem. Secondly, we must strengthen the collection of urban sewage treatment, improve the treatment rate and regeneration rate. Recycling of urban sewage is an effective way to reduce the water pollution, improve the ecological environment and alleviate the shortage of urban water. The establishment of social water cycle of the concept of health, accelerate the construction of urban reclaimed water system.

Build a modern water management system. Increasing the level of water management requires the search for sustained momentum for the efficient functioning of water resources systems. Firstly, the establishment of water conservancy investment and financing mechanism, such as increasing government financial investment, governments at all levels to establish investment and financing platform for water conservancy construction funds, the planned use of foreign capital and a number of preferential policies, the introduction of some utilities income market mechanism. Secondly, give full play to the role of water price leverage, establish and improve the market supply and demand, resource scarcity, ecological damage costs and repair costs of water price formation mechanism. ${ }^{3}$

Protect water security of social. On the one hand to speed up the construction of drinking water safety projects to enhance the level of water benefits of residents. Increase drinking water source protection and pollution prevention and control efforts, establish and improve water quality and health

\footnotetext{
(1) Ochowiak,Marek \& Matuszak,Magdalena, et al. The modified swirl sedimentation tanks for water purification[J]. Journal of environmental management.189(10),2017:22-28.

(2) Zijie Fang, Shengshao Ke. [J], China Water Conservancy, 2015 (06): 8-10 + 27. (In Chinese)

${ }^{3}$ Haining Wang, Huifeng Xue. [J]. China Water Conservancy, 2014, (21): 10-12. (In Chinese)
} 
supervision system and information systems, ${ }^{(1)}$ and develop contingency plans. On the other hand to do a good job of urban waterlogging and flash flood prevention and control work to protect people's lives and property. To promote urban river and drainage pipe network transformation, strengthening drainage pumping station and other infrastructure construction, the comprehensive elimination of waterlogging easy flooded area.

Develop the advanced water culture. Focusing on the restoration and protection of traditional water cultural heritage; increase water culture propaganda, raise residents' awareness of water conservation and expand public participation. The development of water culture combined with "see the mountain, see the water, remember nostalgia" of the new urban development concept. To respect the natural, conform to nature, harmony between man and nature, relying on the existing landscape and other unique scenery, so that the city into nature. So that our city not only "see the mountains, see the water", but also make the sky more blue, the mountains are more green, the water is more clear, there are more resources left to future generations.

\section{Conclusion}

Systematic governance perspective for the water ecological civilization city construction provides an effective way of thinking, water use, water ecological environment, water management, water security, water culture, the five key elements to establish a restoration of urban water ecology, alleviate the water crisis framework And the layout, the government, enterprises and society need to make joint effort, optimize the internal structure of urban water system, improve the efficiency of resource use, and jointly promote water ecological civilization city construction.

\section{Acknowledgments}

This paper is the research result of Shandong provincial level water conservation scientific research and technology promotion project " water resources balances sheet and its application research in public project governance" ( SDSLKY201604 ). It is the key project of Shandong Province Soft Science Research Project (2016RZB01005), and it is the research result of Jinan philosophy and social sciences planning project " construction of eco-city based on environment friendly water conservancy project governance -case in Jinan city" ( JNSK16D04 ).

\section{References}

[1]Smith,Laurence \& Inman,Alex, et al. Mitigation of diffuse water pollution from agriculture in England and China, and the scope for policy transfer[J].Land use policy.61(4),2017:208-219.

[2]Broman,Goran \& Robert,Karl-Henrik, et al. Science in support of systematic leadership towards sustainability[J]. Journal of cleaner production.140(1).2017:1-9.

[3]Ochowiak,Marek \& Matuszak,Magdalena, et al. The modified swirl sedimentation tanks for water purification[J]. Journal of environmental management.189(10),2017:22-28.

[5]Fernandes,J.P \& Freire,M, et al. Using modeling tools for implementing feasible land use and nature conservation governance systems in small islands The Pico Island (Azores) case-study[J].Journal of environmental management.189(10),2017:1-13.

[6]Zijie Fang, Shengshao Ke. [J]. China Water Conservancy, 2015 (06): 8-10 + 27. (In Chinese)

[7] Haining Wang, Huifeng Xue. [J]. China Water Conservancy, 2014, (21): 10-12. (In Chinese)

\footnotetext{
(1) Fernandes,J.P \& Freire,M, et al. Using modeling tools for implementing feasible land use and nature conservation governance systems in small islands The Pico Island (Azores) case-study[J].Journal of environmental management.189(10),2017:1-13.
} 